\title{
Sustainable Neighborhood Assessment: Evaluating Residential Sustainability in Sharjah City's Old Neighborhoods Using the UN-Habitat's Sustainable Neighborhood Principles
}

\author{
Noora A. Chookah ${ }^{1, *}$, Emad Mushtaha ${ }^{2}$, Imad Alsyouf $^{3}$, Abdulsamad Alkhalidi $^{3}$ \\ ${ }^{1}$ Department of Industrial Engineering and Engineering Management, University of Sharjah, Sharjah, UAE \\ ${ }^{2}$ Architectural Engineering Department, University of Sharjah, Sharjah, UAE \\ ${ }^{3}$ Sustainable Engineering Asset Management Research Group, University of Sharjah, Sharjah, UAE
}

Received March 16, 2021; Revised May 20, 2021; Accepted June 6, 2021

\section{Cite This Paper in the following Citation Styles}

(a): [1] Noora A. Chookah, Emad Mushtaha, Imad Alsyouf, Abdulsamad Alkhalidi, "Sustainable Neighborhood Assessment: Evaluating Residential Sustainability in Sharjah City's Old Neighborhoods Using the UN-Habitat's Sustainable Neighborhood Principles," Civil Engineering and Architecture, Vol. 9, No. 4, pp. 1206-1216, 2021. DOI: 10.13189/cea.2021.090422.

(b): Noora A. Chookah, Emad Mushtaha, Imad Alsyouf, Abdulsamad Alkhalidi (2021). Sustainable Neighborhood Assessment: Evaluating Residential Sustainability in Sharjah City's Old Neighborhoods Using the UN-Habitat's Sustainable Neighborhood Principles. Civil Engineering and Architecture, 9(4), 1206-1216. DOI: 10.13189/cea.2021.090422.

Copyright $\odot 2021$ by authors, all rights reserved. Authors agree that this article remains permanently open access under the terms of the Creative Commons Attribution License 4.0 International License

\begin{abstract}
Neighborhood sustainability plays a fundamental role in preserving the city for population growth and future expansion. It also plays a significant role in reducing urban sprawl, one of the main issues facing rapidly growing cities. Ideal sustainable neighborhood planning should address the three sustainability dimensions: environmental, economic, and social sustainability. This paper aims to assess the urban sustainability of the $\mathrm{Al}$ Nasseriya neighborhood in Sharjah City according to the UN-Habitat's five principles of sustainable neighborhoods. The strategy depends on investigative procedures utilizing information examination, site visits, and data analysis. Conventionally, the study is based on the UN-Habitat's guidelines on practical neighborhoods that state that neighborhoods should be minimal, coordinated, and associated. They suggest a quantitative analysis scope as a maintainability investigation of neighborhoods using five primary administrators: an effective road network, high-density population, mixed land uses, social blending, and limited land-use specializations. The assessment shows that Sharjah's physical urban context has several shortcomings related to the UN-Habitat's criteria that
\end{abstract}

should be addressed. The results of the study demonstrate the critical issues affecting urban sustainability practice in the study area. Finally, urban improvement guidelines are recommended to advance development and amplify proficiency.

Keywords Sustainable City, Sustainable Neighborhoods, Urban Sustainability Assessment, Sustainable Urban Development, UN-Habitat, Sharjah

\section{Introduction}

We are currently living in a world that favors the growth of urban centers since one out of two residents presently lives in an urban area. By 2040, this will increase to $80 \%$, hence making urban development necessary to arrive at the worldwide maintainability objective [1]. Over the past decades, the design of neighborhoods has been of a typical engineering style focusing on surveying and lot yield efficiency. These 
approaches have shaped unsustainable neighborhoods [2]. Today, the main goal is to design a framework for communities that is environmentally, socially, and economically sustainable [3]. The world's urban areas and their residents need a sustainable urban center and communities that are designed and improved upon in a significantly more profitable way to produce genuinely necessary positions, thus making the earth a more comfortable place to live in [4]. Information gathering and better exploration are expected to make urban communities more successful in the development of a genuine study. The world needs a successful urban strategy, authority, and methodology.

Expanded urbanization will cause urban sprawl. Therefore, living cities will not just need to be designed within urban limits. Living communities need to be made alluring, well-served, and safe. Few effective models promote livable and sustainable communities. Moreover, the UN-Habitat's accentuation of the spatial arrangement and planning of urban communities has been accelerated. Therefore, making the five sustainable planning principles more straightforward will ensure that new and inventive methods will be infused into authentic urban design. Many centers that focus on this will be able to shape the development of neighborhoods such as Al Nasseriya in Sharjah. These objectives may include a proper street network, high-density population, mixed community, and diverse uses of land.

\subsection{Sustainable Neighborhoods}

A neighborhood is an area characterized as the arranging unit of a city [5]. It is viewed as the most significant urban component that develops the territory's social and financial supportability. Neighborhood planning and design create a specific physical and social reality that significantly impacts the environment and the people who live there [6]. The characteristics of a practical neighborhood, including its road network, green spaces, work opportunities, shops, and public facilities, help shape the city and influence residents' satisfaction. The way in which these elements are distributed impacts neighborhood sustainability. For example, research has shown that the availability of different services and goods (e.g., diverse land uses) allows residents to participate in society (i.e., meets the residents' needs for recreation, jobs, health, social activities, etc.), thus improving economic and social sustainability [7]. On the other hand, a lack of these opportunities encourages motorized travel, which affects environmental sustainability through, for example, noise and air pollution and climate change [8][9]. Hence, the meaning of sustainable neighborhood development is to balance the environmental, social, and economic requirements that are linked with urban development measures [10]. Churchill and Baetz [11] developed several strategies for a sustainable neighborhood that include factors such as "population density, alternative modes of transportation systems, community agriculture, water re-use, and green building techniques" [12]. In supporting feasible neighborhoods, the standards of past urban methodologies and hypotheses aim to [13][14][15]:

1. Promote high-density urban development and reduce urban sprawl.

2. Promote socially equivalent and flourishing networks in monetarily reasonable ways.

3. Maximize land proficiency and advance the utilization of land.

4. Decrease vehicle reliance and provide interconnected roads to offer well-being, productivity, and strolling, cycling, and driving opportunities.

5. Foster nearby utilization and neighborhood creation.

6. Offer an assortment of parcel sizes and lodging types that satisfy the various lodging needs of the network at densities viable for the nearby administrations' arrangements.

7. Encourage community and stakeholder collaboration in development decisions.

\subsection{The United Arab Emirates' Sustainable Development Plans}

The United Arab Emirates (UAE) is considered one of the developing countries that adopted a leading political agenda to achieve sustainability in all development plans, including housing. Fortunately, urban spaces and building designs in the UAE contributed toward sustainability [16]. Accordingly, it was ranked as the ninth country among the top 10 countries with the largest energy-efficient development outside the United States [17]. The UAE has launched several ambitious initiatives, such as Estidama and Masdar, to encourage sustainability in the building and housing sectors. This made the UAE one of the countries that pioneered the adoption of the sustainability agenda [18]. On the other hand, these agendas are successful for building communities in the design and construction stages. A successful example of a sustainable neighborhood in the UAE is the new sustainable city in Dubai, which was established in 2014 to implement the concept of sustainability in real residential areas [6]. Dubai's sustainable city represents a unique example of green transportation; it involves horse tracks, bicycle tracks, electric cars, and a car-free neighborhood. The city's electricity is produced through on-site photovoltaic generation on each house. Additionally, the city integrates urban agriculture locally to produce organic food. Further, wastewater is recycled to be used for the landscape and urban farms [19]. Moreover, Abu Dhabi launched Masdar City in 2018, which was considered one of the most sustainable urban cities in the world, aiming to be the first zero-carbon-emission and zero-waste city in the next decades. All buildings in Masdar City use $40 \%$ less 
energy compared to normal buildings [20]. Several approaches have been adopted internationally and locally to achieve sustainable neighborhood design. Some research presented different sustainability principles such as Leadership in Energy and Environmental Design (LEED) for Neighborhoods, which is more environmentally oriented [21]; Regional Rating Systems Development (Qatar Sustainability Assessment System and Estidama Pearl Rating System) that adds a sociocultural aspect to the environmental approach [22]; the Circles of Sustainability principles that emphasize economic and political approaches [23]; and, finally, the UN-Habitat's five sustainable neighborhood principles, which focus on urban design [13]. The UN-Habitat proposed an approach that refines existing sustainable urban planning theories to develop a new sustainable relationship between people and urban space and increase urban land value. This approach is based on five principles that support three key features of sustainable neighborhoods and cities: being compact, integrated, and connected [24]. These principles could be used for new urban settlements, as well as urban renewal projects. Many city planners nowadays concentrate on assessing new communities' urban conditions more than the existing urban areas, leaving the old existing neighborhoods unsustainable. The UN-Habitat approach is the best option for this study, as it is an international approach that can be applied to any region.

\subsection{UN-Habitat: The Five Principles}

The United Nations Human Settlements Program established a new approach that enriches the current sustainable urban planning theories for sustainable communities. This approach, as mentioned earlier, is built on five principles that support three key features of sustainable neighborhoods and cities: compact, integrated, and connected [13]. The five principles are:

- Principle 1: Creating an adequate and efficient street network. This principle aims to develop a suitable and sufficient street network for vehicles, pedestrians, cyclists, and public transport. It includes a street hierarchy, arterial routes, and local streets that serve varying traffic rates. The street network should cover at least $30 \%$ of the total land, with 18 $\mathrm{km}$ of street per $\mathrm{km}^{2}$.

- Principle 2: Adapting to a high-density population, which responds directly to the rapid global population growth and urbanization, this principle aims to promote a sustainable urban extension and avoid urban sprawl. Principle 2 requires that the land should be occupied by at least 15,000 people per $\mathrm{km}^{2}$; which is 150 people/Ha.

- Principle 3: Allowing for mixed land uses. Economic use should be allocated to at least $40 \%$ of the total land area. Principle 3 aims to develop a compatible range of activities and land use in proper locations with the flexibility to adapt to market changes over time. It also aims to support local jobs, increase the local economy, provide closer public services, and support mixed communities.

- Principle 4: Social mixing by providing houses in different price ranges to accommodate people with various income levels. Houses in different price ranges should be available to accommodate different incomes; $20-50 \%$ of the residential floor area should be allocated to low-cost housing; and each tenure type is to be less than $50 \%$ of the total. This principle seeks to build up relationships among the various social classes living in the same community, encouraging healthy social networks.

- Principle 5: Limiting specialized land use, which means limiting the singular use of blocks or neighborhoods. Single-function blocks should not cover more than $10 \%$ of any neighborhood. Principle 5 aims to adjust the use of functional zoning to implement the policies of mixed land uses.

Table 1 shows the equations of the UN-Habitat methodology. The five principles provide quantitative measurements that could be used to analyze a neighborhood. These principles are interconnected and support each other.

Table 1. The equations and units of the UN-Habitat's five sustainable neighborhood planning principles. Source: [13]

\begin{tabular}{|c|c|c|}
\hline Principle & Formula & Unit \\
\hline Principle 1 & $\frac{\text { Street land use }}{\text { Total floor area }}$ & $(30-45 \%)$ \\
\hline Principle 2 & Population density & $\left(15-60 \mathrm{k}\right.$ people $\left./ \mathrm{km}^{2}\right)$ \\
\hline \multirow{2}{*}{ Principle 3} & $\frac{\text { Economic floor area }}{\text { Total floor area }}$ & $(40-60 \%)$ \\
\hline & $\frac{\text { Residential floor area }}{\text { Total floor area }}$ & $(30-50 \%)$ \\
\hline \multirow{2}{*}{ Principle 4} & $\frac{\text { Single }- \text { tenure }}{\text { Residential floor area }}$ & $(0-50 \%)$ \\
\hline & $\frac{\text { Affordable housing }}{\text { Residential floor area }}$ & $(20-50 \%)$ \\
\hline Principle 5 & $\frac{\text { Single }- \text { function block area }}{\text { Neighbourhood area }}$ & $(0-10 \%)$ \\
\hline
\end{tabular}


Thus, it is important to concentrate on the UN-Habitat's planning principles to achieve comprehensive planning for a sustainable neighborhood. Dehghanmongabadi [25] presented two examples of the best sustainable neighborhoods, Västra Hamnen and Ekostaden Augustenborg in Malmö City, Sweden, which achieves all of the UN-Habitat's planning principles. The study also mentioned some solutions that the city followed to achieve the sustainability planning criteria, such as giving priority access to pedestrians and cyclists, providing underground floors in multi-story buildings for car parks, increasing open public spaces and urban parks, and constructing sites on reclaimed or formerly developed industrial land. Locally, El-Khateeb [6] analyzed the implementation of the UN-Habitat's principles for sustainable neighborhood design in Dubai's sustainable city. The results showed that the city implemented most of the principles; however, it did not achieve Principle 2, where a mixed, high-density population was expected in Dubai's 5,000,000 square-foot city. It also did not meet the target for Principle 4 since the low-cost housing area in Dubai was only $10 \%$. Moreover, Ibrahim [26] analyzed Sharjah's sustainable city, which is still under construction and was designed to be the first zero-net-energy community in Sharjah. The study was based on assumptions and expectations, mostly referring to the data of Dubai's sustainable city since the same developer conducted both projects, which were expected to have the same features. The study showed that Sharjah's sustainable city achieved Principle 1 since the city was designed with a total street area of $30 \%$, as well as Principle 4 since it encourages people of myriad nationalities to be part of the community and has affordable prices for all units.

Nowadays, housing and urban planning authorities in Sharjah have considered sustainability in the design of most of the new Emirati residential districts, which helps to present a positive image of the emirate. On the other hand, poor living conditions have emerged in various old residential neighborhoods. The government of Sharjah acknowledged this issue and is working on developing a strategic city plan that will improve the quality of the living environment in the old neighborhoods for the long-term stability of economic, environmental, and social values to achieve sustainable development. Therefore, the research aims to evaluate one of the old neighborhoods in Sharjah, Al Nasseriya, in terms of urban sustainability. The study's main objective is to assess the urban planning conditions of the selected neighborhood by utilizing urban sustainability indicators, as per the UN-Habitat's five principles of sustainable neighborhoods, and develop guidelines for further urban sustainable development.

\section{Research Method}

Table 2. The levels of intervention and associated potential types of change. Source: Authors

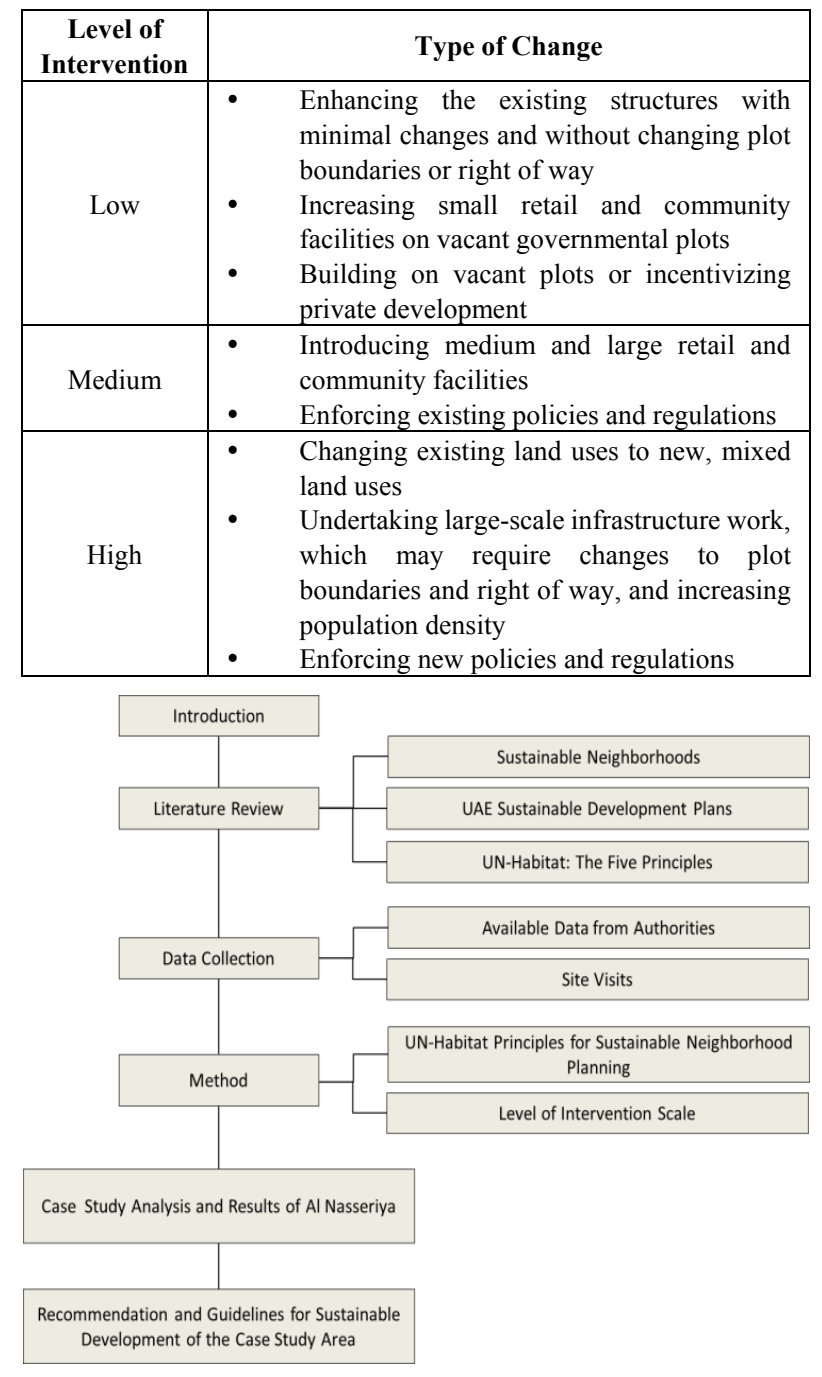

Figure 1. Research flow diagram. (Source: Authors)

In this study, the UN-Habitat's principles were used to evaluate the selected neighborhood's current urban planning conditions. Descriptive methodology was used to present the existing conditions using data collection and analysis, as well as site visits. The initial evaluation was based on the UN-Habitat's sustainable neighborhood principles, namely being compact, integrated, and connected. The UN-Habitat recommended an approach that summarizes and refines existing sustainable urban planning theories to develop a sustainable relationship between urban spaces and residents. The equations for the five principles were presented in Table 1 . The results of these equations were compared with the UN-Habitat's standards for sustainable neighborhood planning. The differences between the case study and the UN-Habitat's standards represent the level of change needed to achieve the criteria. To understand the level of change that could be implemented, each principle was measured on an 
intervention scale from low to high, as shown in Table 2. The table describes the potential type of change at each point of the intervention scale. To be effective, the intervention is not limited to physical work but also involves regulatory and policy changes and market forces. Figure 1 shows the research flow diagram of this study.

\section{Case Study Analysis and Results}

\subsection{Al Nasseriya Neighborhood}

The study's selected area is Al Nasseriya neighborhood, a mixed-use neighborhood close to the city center, with a population density of 96 people/Ha and an area of 737,850 $\mathrm{m}^{2}$ [27]. The area was previously a residential neighborhood for nationals, who migrated further away from the city center to emirate's hinterlands, leaving the area to non-nationals. When Emirati households were granted land in new neighborhoods, they rented their current houses to expatriate families and moved to their new homes. As the houses in the old neighborhoods aged, most expatriate families moved, and the neighborhood became occupied by single expatriates who most work as laborers. Over time, some houses became dilapidated, so they were replaced with multi-story apartment buildings. The neighborhood now comprises residential and retail units, staff accommodation, detached housing, and educational and religious facilities. The neighborhood has low level of built public realm compared to other neighborhoods in Sharjah. Figure 2 shows a map of AlNasseriya neighborhood and its urban form, Figure 3 illustrates its land-use distribution, and Figure 4 shows the street network that comprises $20 \%$ of the total neighborhood area, $10 \%$ of which is paved [27].

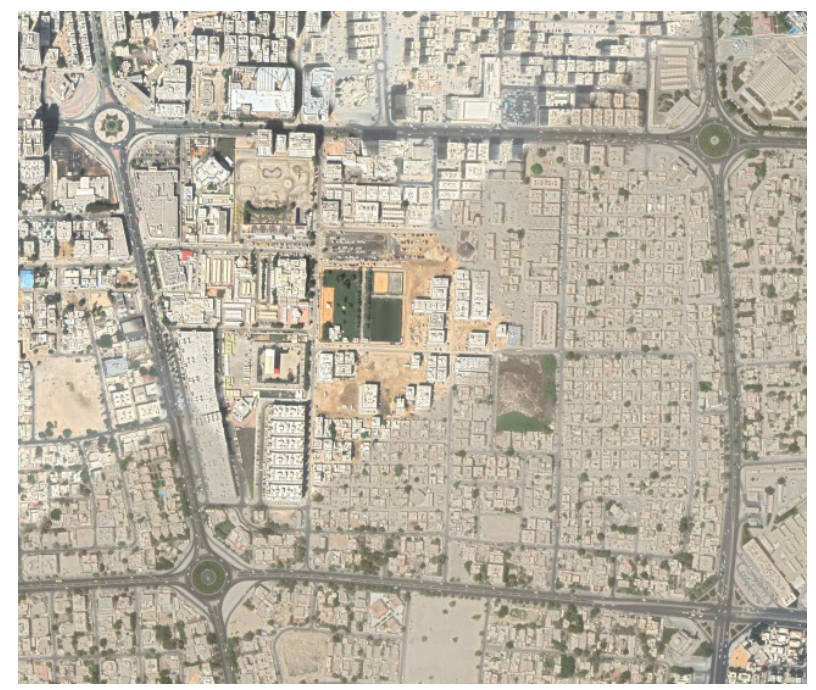

Figure 2. An aerial view of Al Nasseriya. (Source: Google Earth Pro)

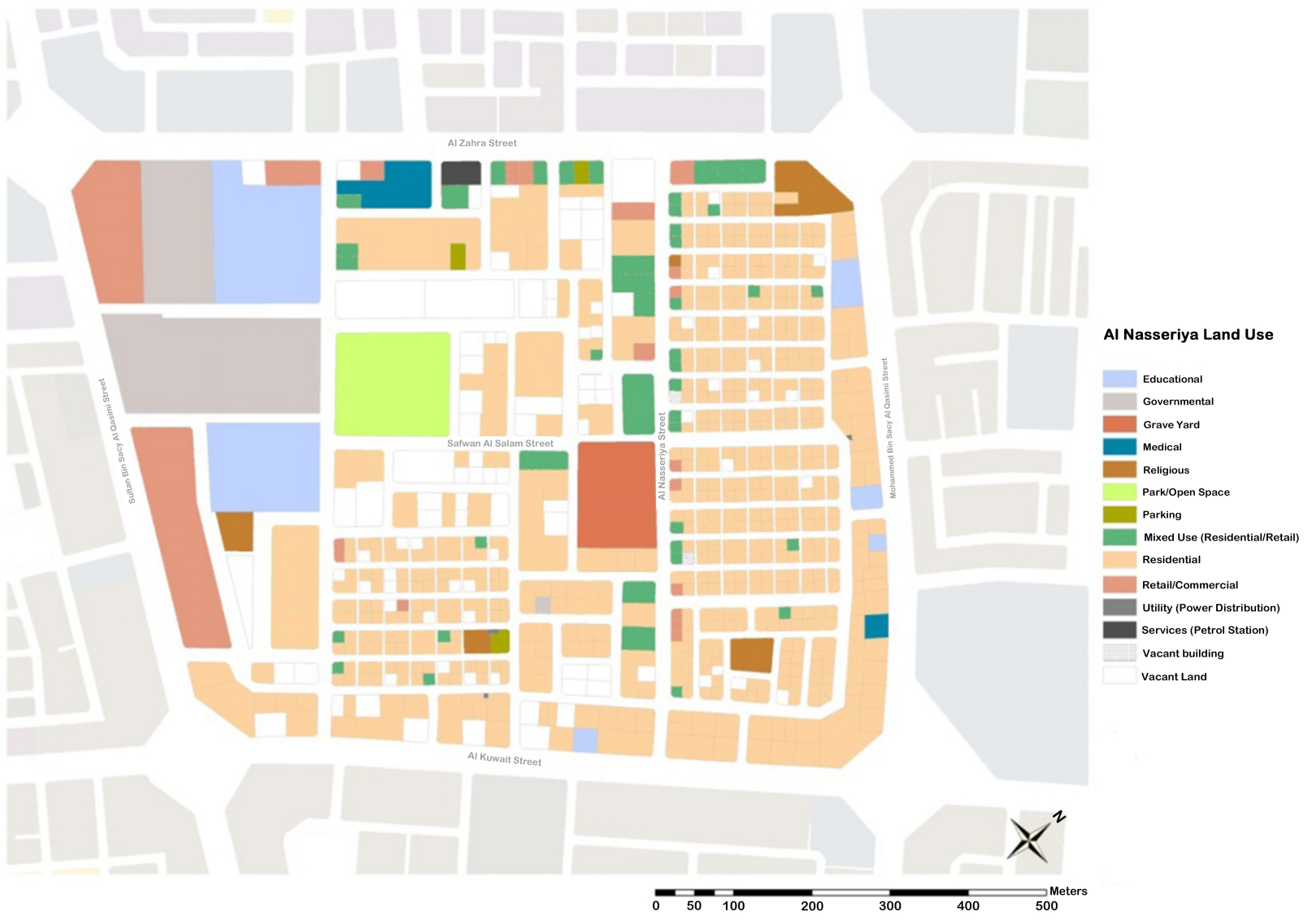

Figure 3. The land-use plan of Al Nasseriya. (Source: [27] [28]) 


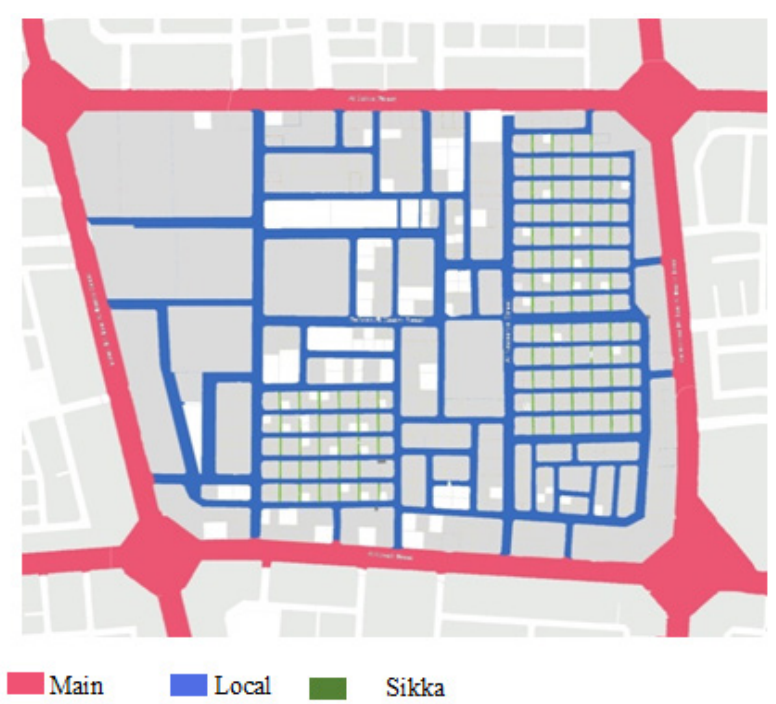

Figure 4. The street network in Al Nasseriya. (Source: [27])

Table 3 shows the area and percentages of the land uses for the total area of Al Nasseriya. Residential use has the highest percentage at more than $30 \%$ of the neighborhood's total area. The lowest percentage is for the petrol station and graveyard at $2 \%$, which is sufficient for one neighborhood. Parks and open spaces cover less than $3 \%$ of the land [27], which is very low and does not encourage physical and social activities.

Table 3. Allocated areas and the percentages of different land uses in $\mathrm{Al}$ Nasseriya. Source: [27]

\begin{tabular}{|c|c|c|}
\hline Land Use & Area $\mathbf{( m}^{\mathbf{2}} \mathbf{)}$ & $\mathbf{\%}$ of the Total Area \\
\hline Residential & 243,145 & $33.0 \%$ \\
\hline Commercial & 39,917 & $5.4 \%$ \\
\hline Mixed Use & 63,845 & $8.6 \%$ \\
\hline Open Spaces & 19,324 & $2.6 \%$ \\
\hline Community Facilities & 56,547 & $7.6 \%$ \\
\hline Governmental & 95,984 & $13.0 \%$ \\
\hline Graveyard & 13,551 & $1.8 \%$ \\
\hline Vacant Land & 56,782 & $7.6 \%$ \\
\hline Petrol Station & 1,516 & $0.2 \%$ \\
\hline Paved Streets and Parking & 78,037 & $10 \%$ \\
\hline Unpaved Streets & 69,202 & $10 \%$ \\
\hline
\end{tabular}

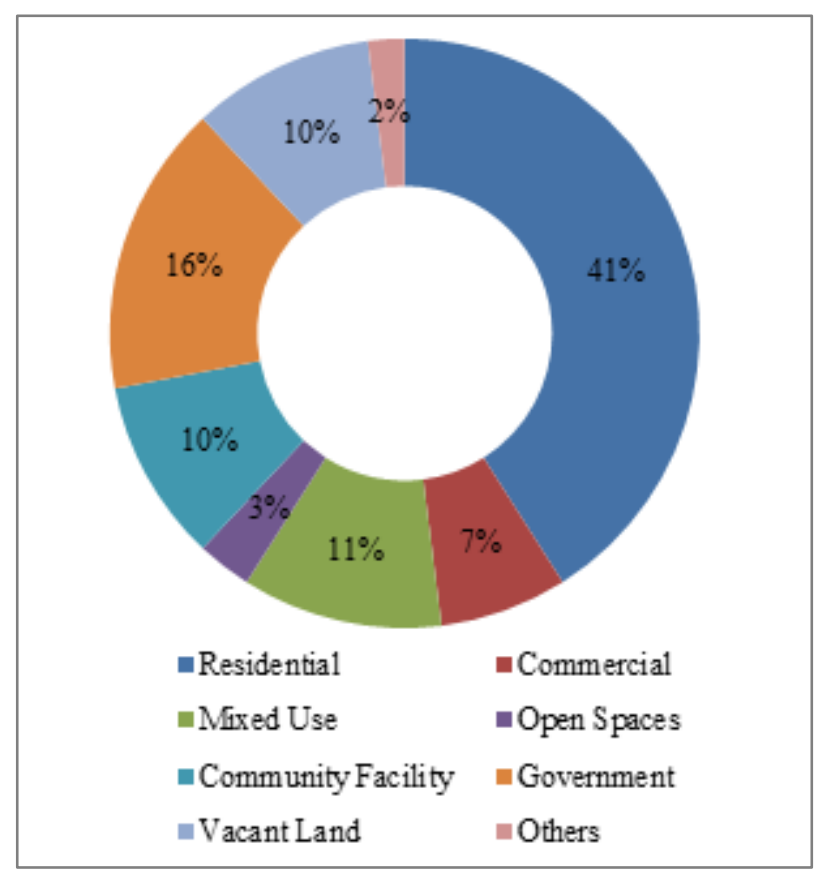

Figure 5. Land-use percentages, excluding the road network. (Source: [27])

\subsection{Results and Discussion}

Based on the UN-Habitat's urban sustainability methodology shown in Table 1, as well as the site visits, the neighborhood is characterized by the following:

\section{- $\quad$ Principle 1: Inadequate Space for the Street Network}

The paved street network occupies $10 \%$ of the land, while the minimum according to the UN-Habitat's standards is $30 \%$. According to the site observation shown in Figure 6, people walk and cycle on streets, although they lack safety and development strategies. The public transport network is accessible to most of the residents. On the other hand, it was observed that the area lacks green and open spaces since only one central park can be seen. The open public spaces cover only $2.6 \%$ of the land, which should be increased by more than $12 \%$ to provide adequate social and interactive spaces for residents. Principle 1 needs a high level of intervention to be achieved, which requires infrastructure work and right of way adjustments. 


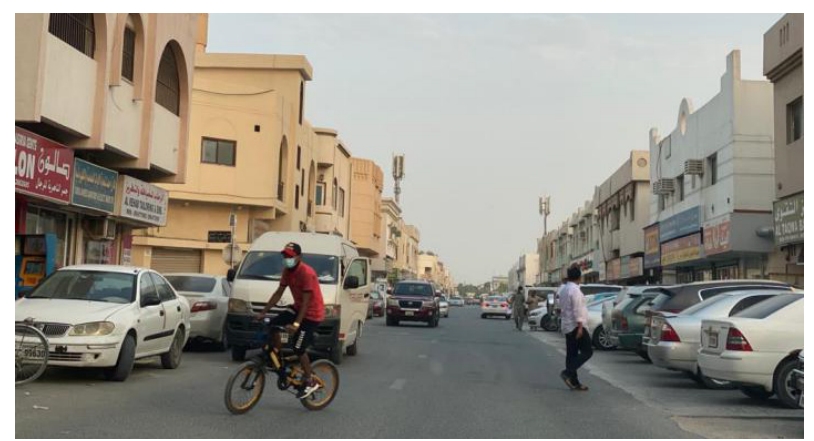

Figure 6. Walking and cycling in Al Nasseriya. (Source: Authors)

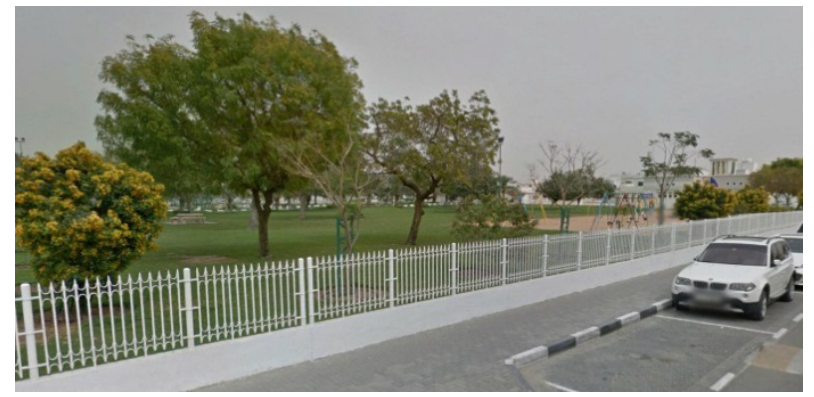

Figure 7. Al Nasseriya Park, an open public space. (Source: Authors)

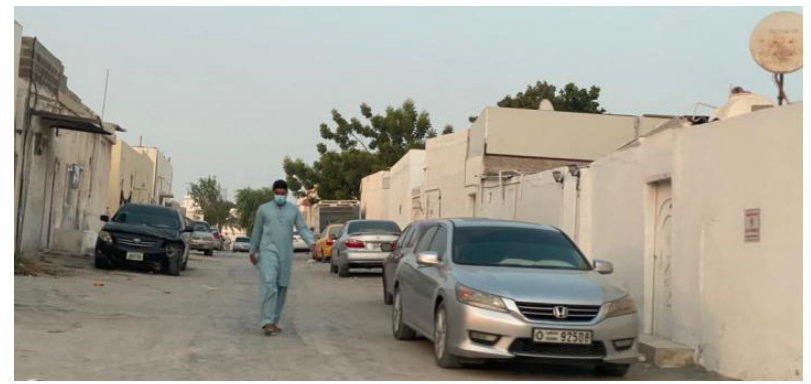

Figure 8. An unpaved street in Al Nasseriya. (Source: Authors)

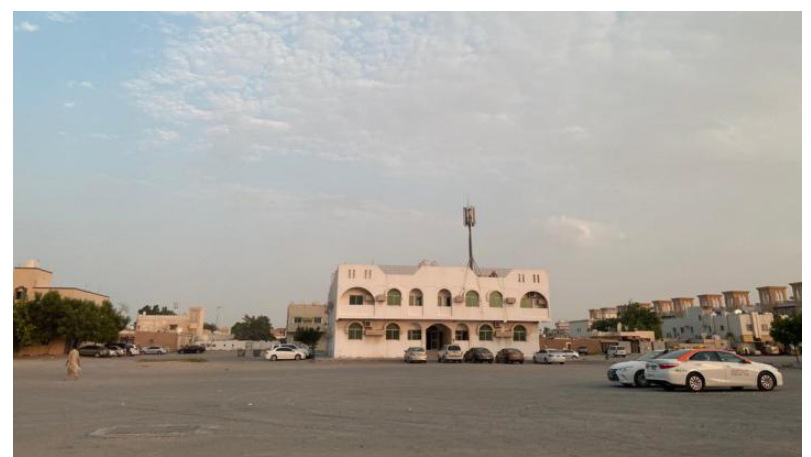

Figure 9. Large vacant land. (Source: Authors)

\section{- $\quad$ Principle 2: Population Density}

Al Nasseriya has a medium population density of 99 people/Ha, which does not achieve the objective of Principle 2, namely having a high-density community. During the site visits, it was noticed that there is a limited number of mid- and high-rise buildings in the area. The neighborhood has $7.2 \%$ of buildable vacant land, which impacted on the population density to be less than the principle standard. Furthermore, the community was built without taking into consideration future urbanization. To achieve Principle 2, a low to high level of intervention is required to increase population density. Some policies might be established that will change the demographics of the area.

\section{- $\quad$ Principle 3: Mixed Land Uses}

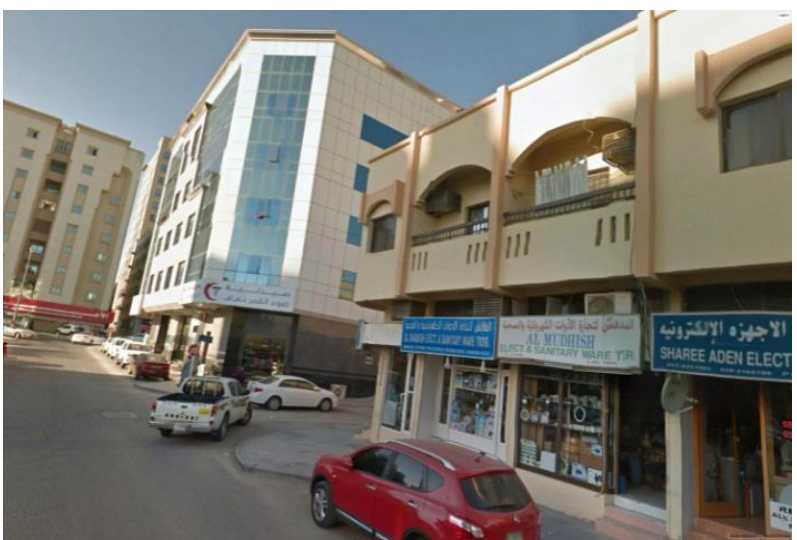

Figure 10. A mixed-use building. (Source: Authors)

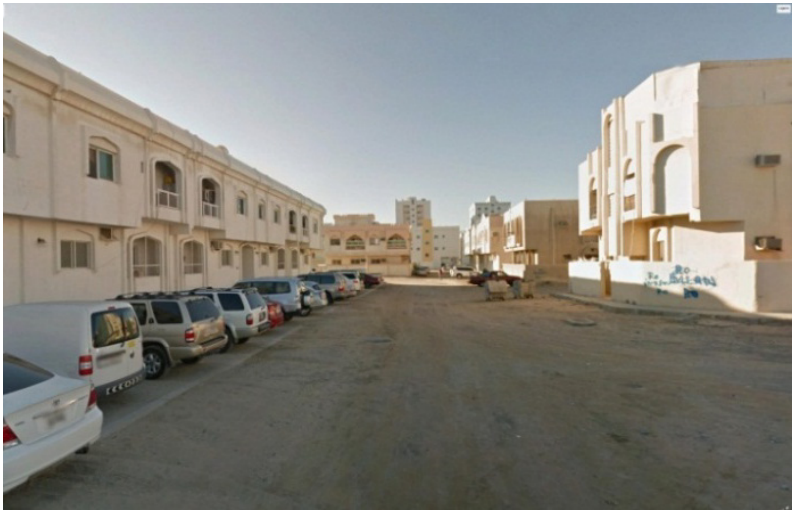

Figure 11. Residential buildings and an unpaved road. (Source: Authors)

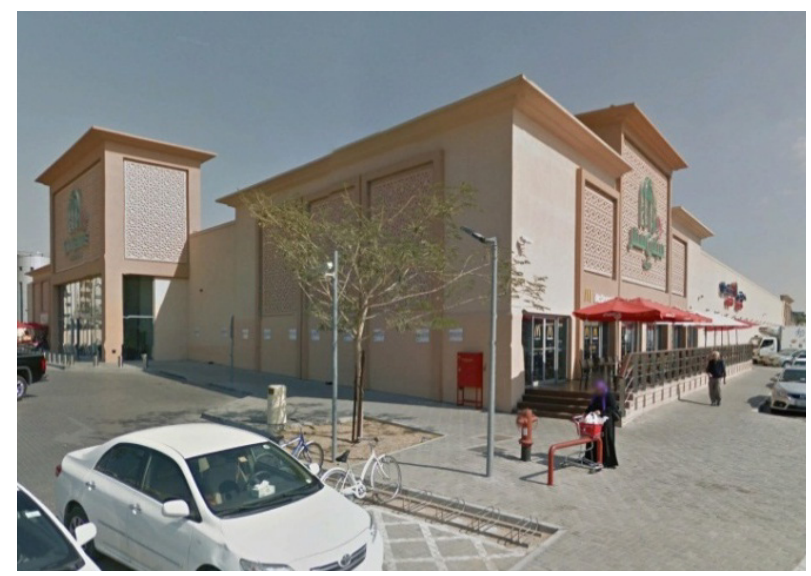

Figure 12. A Commercial building. (Source: Authors)

Approximately $41 \%$ of the land is allocated to residential use, while $14 \%$ is allocated to retail and commercial use. The economic area should be increased 
by $26 \%$ to achieve the UN-Habitat's standard of mixed land uses. This could be done by introducing small to large retail and community facilities with a medium level of intervention. Al Nasseriya is in the city center close to coastal roads, making it a suitable location to attract more users.

\section{- $\quad$ Principle 4: Social Mix}

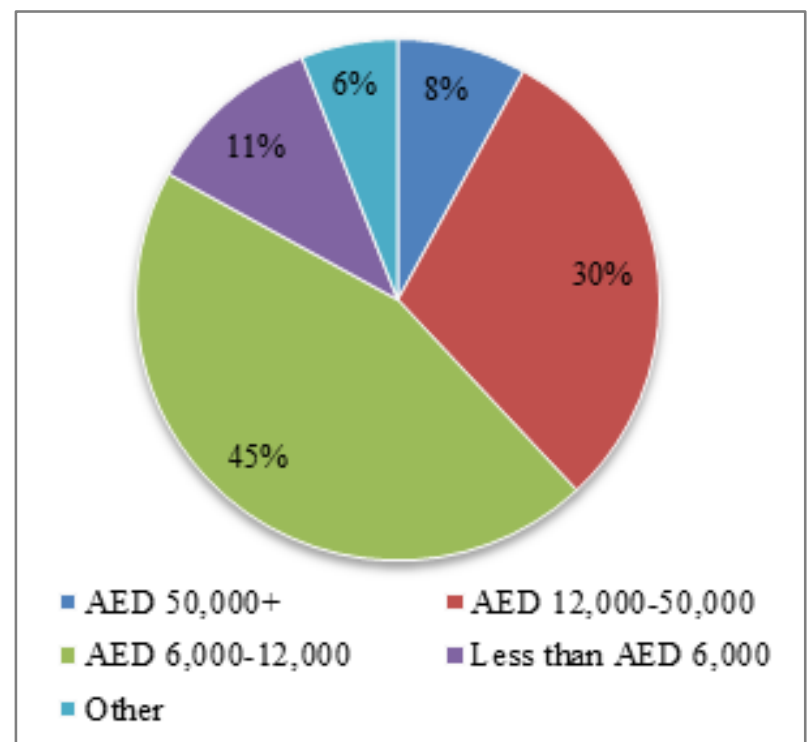

Figure 13. The income levels of Al Nasseriya residents. (Source: [28])

Due to some irregularities and informal rentals, it was difficult to measure the percentage of single-tenure and affordable housing. However, a previous study done in $\mathrm{Al}$ Nasseriya measured the economic level of the families living here, as shown in Figure 13. Thus, the percentage of affordable housing is assumed to be $86 \%$, in which the income level of the householders is less than AED 50,000 [28]. This percentage exceeds the standard limit and indicates that people from the working class make up the majority of the community, which was noticed during the site visit. This number needs to be balanced by attracting local householders to attain a healthy social mix. The needs of the local residents should be taken into consideration to develop the area, as well.

This will require a medium level of intervention, as some enhancements to public realm and infrastructure are needed. Introducing facilities and increasing retail and economic land uses could also attract more people.

\section{- $\quad$ Principle 5: Limited Land-Use Specialization}

This principle aims to limit the single-use of blocks. In Al Nasseriya, single-use blocks represent $46 \%$ of the neighborhood area. This principle is related to Principle 3 regarding mixed land uses, which aims for a balanced mix of land uses. This needs a high level of intervention to be achieved, as it requires changing the existing land uses.

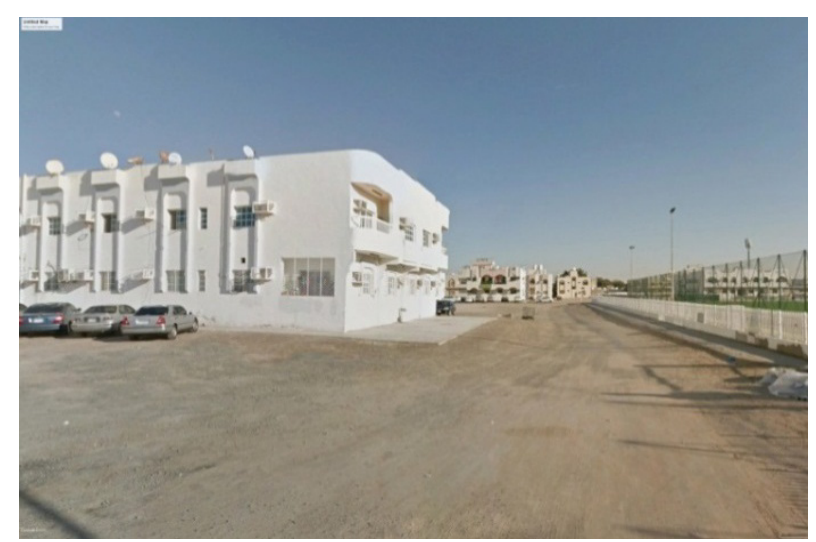

Figure 14. Single-function residential blocks close to Al Nasseriya Park, with an opportunity to add retail shops on the ground level. (Source: Authors)

The chart in Figure 15 shows the differences between the UN-Habitat's standards and the outcomes of this study. These differences indicate the level of change needed to achieve the numerical standard values. As a part of the redevelopment strategy, it is essential to prioritize improvements by implementing low- to medium-scale interventions. 


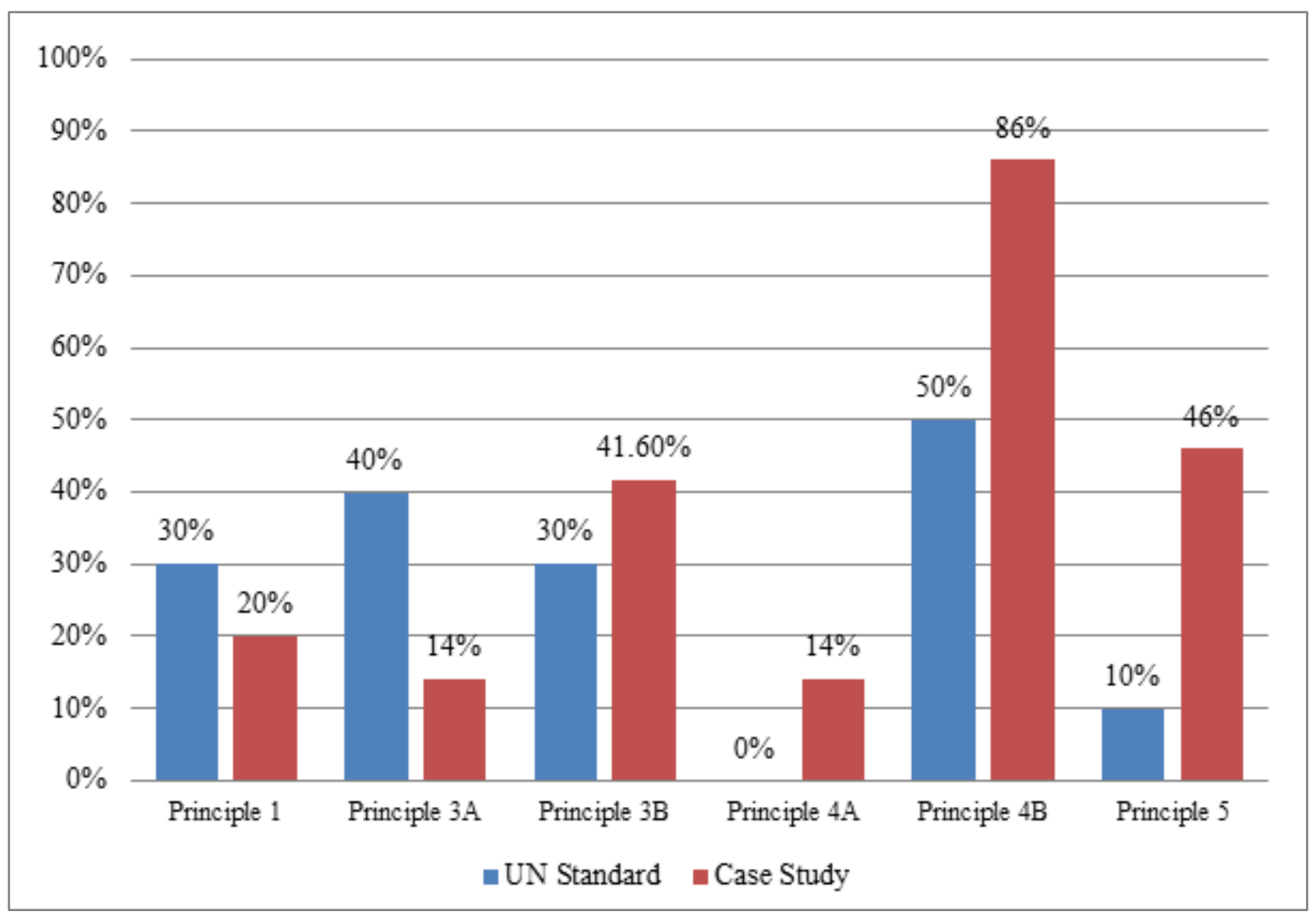

Figure 15. The differences between the UN-Habitat's five principles and the case study's findings. (Source: Authors)

Table 4. Summary of the assessment findings. Source: Authors

\begin{tabular}{|c|c|c|c|c|c|}
\hline Principle & Formula & Standard & Case Study & $\begin{array}{c}\text { Difference } \\
\text { (Level of Change) }\end{array}$ & $\begin{array}{c}\text { Level of } \\
\text { Intervention }\end{array}$ \\
\hline \multirow{2}{*}{ Principle 1 } & $\frac{\text { Street land use }}{\text { Total floor area }}$ & $(30-45 \%)$ & $10 \%$ & $20 \%$ & High \\
\cline { 2 - 6 } & Open public spaces & $(15-20 \%)$ & $2.6 \%$ & $12.4 \%$ & High \\
\hline \multirow{2}{*}{ Principle 2 } & Population density & 150 people/ha & 96 P/Ha & 54 people/Ha & High \\
\hline \multirow{2}{*}{ Principle 3 } & $\frac{\text { Economic floor area }}{\text { Total floor area }}$ & $(40-60 \%)$ & $14 \%$ & $26 \%$ & Medium \\
\cline { 2 - 6 } & $\frac{\text { Residential floor area }}{\text { Principle 4 floor area }}$ & $(30-50 \%)$ & $41.6 \%$ & - & Achieved \\
\cline { 2 - 6 } & $\frac{\text { Single }- \text { tenure }}{\text { Residential floor area }}$ & $(0-50 \%)$ & $14 \%$ & $36 \%$ & Medium \\
\hline \multirow{2}{*}{ Principle 5 } & $\frac{\text { Sffordable housing }}{\text { Residential floor area }}$ & $(20-50 \%)$ & $86 \%$ & $36 \%$ & High \\
\hline
\end{tabular}

\section{Conclusion and Recommendations}

The absence of comprehensive sustainable planning strategies in neighborhood design leads to critical urban planning issues such as urban sprawl. Some of the latest sustainable neighborhood planning principles are the UN-Habitat's five principles; these principles can be used while designing a neighborhood or when evaluating existing cities and neighborhoods. Hence, this research aimed to identify the main issues affecting the urban sustainability of Sharjah's old neighborhoods using the UN-Habitat's principles, which provide quantitative sustainability indicators. The study was done in the Al Nasseriya community, which is considered an old neighborhood in Sharjah's city center. According to the UN-Habitat's evaluation equations and the site visits, most of the urban sustainability indicators are not within suitable ranges in Al Nasseriya. The street network in the selected neighborhood covers only $10 \%$ of the total area, which requires major infrastructure work to meet the 
target. There are a limited number of open public spaces, which need to be increased by at least $12.4 \%$. The population density in the selected neighborhood is 96 people/Ha, which is less than required. Although the neighborhood is socially mixed, comprising different nationalities, its affordable housing exceeds the standard limit. Balancing single-tenure and affordable housing is required in the area, which can be achieved by attracting local residents through satisfying their needs. Moreover, its economic area covers only $14 \%$ of the total area, which is $26 \%$ less than the minimum of the standard. To achieve Principles 3 and 5, a variety of land uses should be added and mixed in the selected neighborhood, and one block should have a combination of different but compatible land uses. The mixed land-use concept suggests a combination of housing, commercial, retail, industrial, recreational, office, and other land uses.

On the other hand, these five principles do not represent a comprehensive theory for sustainable urban planning and only cover a few basic characteristics. The five principles can be used initially to judge whether a neighborhood possesses the capacity for sustainable development and can be used in the preliminary stages of drafting urban scenarios and urban plans. Moreover, the following points are recommended for Al Nasseriya's successful and sustainable urban renewal development:

1. Develop an internal road network implementation plan and interconnected, accessible, and safe pedestrian and bicycle networks to encourage walking and cycling.

2. Create more open public spaces on available vacant plots and allocate some areas between residential buildings to pocket parks that all age groups are able to safely access.

3. Evacuate violators of and residents without rental contracts or landownership and provide different housing tenures by balancing the ownership-to-rented ratio.

4. Provide housing with different building sizes for different social classes, and redefine building legislation, including regarding setbacks, and propose that building heights be increased to develop a high-density community.

5. Upgrade utilities and services and replace decayed built structures to attract people and increase the population density and introduce more retail and community facilities and encourage local businesses.

6. Introduce mixed land-use zoning as per the market demand and cities' urban by-laws and regulations and assign several compatible functions and land uses to a single block and combine mixed-use activities within residential blocks according to the community's needs.

7. Involve the community in the planning and redevelopment process to identify their needs and develop collaboration programs that include the government and private sectors in the neighborhood renewal process.

\section{REFERENCES}

[1] Karban, A. S. (2014). Developing a framework for neighborhood-level urban sustainability assessment in Saudi Arabia. The University of Texas at San Antonio.

[2] Bijou, D., Saville-Smith, K., \& Lietz, K. (2008). The Importance of Urban Neighborhourhood sustainability in New Zealand. Ecocity World Summit 2008 Proceedings.

[3] Gisborne/New Gisborne Outline Development Plan. (2009). Revised Final Report.

[4] More, B. A. (2017). Urban planning, neighborhoods, and social cohesiveness: a socio-cultural study of expatriate residents in Dubai (Doctoral dissertation, University of Salford).

[5] Searfoss L. (2011). Local perspectives on HUD's neighborhood stabilization program. Report for national community stabilization trust. University of Illinois at Urbana-Champaign.

[6] El-khateeb, S. (2019). Sustainable Neighborhoods in Arab world; a Path Towards Sustainability: The Case of the Sustainable City in Dubai. The Academic Research Community Publication. IEREK press.

[7] Hine, J., Kamruzzaman, M., Blair, N. (2012). Weekly activity-travel behaviour in rural Northern Ireland: Differences by context and socio-demographic. Transportation, 39, 175-195.

[8] Jabareen, Y. (2006). Sustainable Urban Forms: Their Typologies, Models, and Concepts. J. Plan. Educ. Res, 26, 38-52.

[9] Newman, P.; Kenworthy, J. (1996). The Land Use-Transport Connection: An Overview. Land Use Policy, $13,1-22$.

[10] Al-Hagla, K. (2008). Towards A Sustainable Neighborhood: The Role of Open Spaces. International Journal of Architectural Research, 2(2), Pp. 162-177.

[11] Churchill, C. \& Baetz, B. (1999). Development of decision support system for sustainable community design. ASCE Journal of Urban Planning and Development, 125(1), pp. 1735 .

[12] Engel-Yan, J., et al. (2005). "Toward sustainable neighbourhoods: the need to consider infrastructure interactions." Canadian Journal of Civil Engineering 32.1, pp. 45-57.

[13] UN-Habitat. (2014). A new strategy of sustainable neighbourhood planning: Five Principles, Discussion Note 3, Urban Planning. [online], Retrieved from; https://unhabitat.org/wp-content/uploads/2014/05/5-Principl s web.pdf.

[14] Teed, J., Condon, P., Muir, S., and Midgley, C. (2013). Sustainable urban landscapes, neighbourhood pattern 
typology. Retrieved June 11, 2014 from http://www.jtc.sala.ubc.ca/projects/SDRI/typ.pdf.

[15]Falk, N., and Carley, M. (2012). Sustainable urban neighborhoods Building communities that last. Retrieved June 10, 2014 from

http://www.jrf.org.uk/sites/files/jrf/sustainable-urban-neighb ourhoodsfull.pdf

[16]El-Bana, N., Selim, S.H. \& Taleb, H. (2015). Optimizing sustainability at an urban level: A case study of Dubai Sustainable City. Sustainable Development Planning VII, 1, pp. 985-995.

[17] Issa, N. \& Al Abbar, S. (2015). Sustainability in the Middle East: Achievements and challenges. International Journal of Sustainable Building Technology and Urban Development, 6(1), pp. 34-38.

[18] Awad, Z., E. (2013). Comparing Urban Sustainability in Two Neighborhoods in Khartoum-Sudan. World Economic and Social Survey, 10.

[19] Diamond Developers, The sustainable city: A project by Diamond Developers. [online], retrieved from; https://www.thesustainablecity.ae/.

[20] Bakr, A. \& Lewis, B. (2010). Finding a balance: UAE eyes sustainable growth, Reuters. [online], retrieved from; https://www.reuters.com/article/us-emirates-sustainability/fi nding-a-balance-uae-eyes-sustainable-growth-idUSTRE69C 5F620101013.

[21] Congress for the New Urbanism, (2014), Natural Resources Defense Council, and the U.S. Green Building Council, LEED 2009 for Neighborhood Development, Green Building Council, USA.

[22] QSAS. (2010). Qatar Sustainability Assessment System. Qatar, Gulf Organization.

[23] James, P Magee. L., Scerri, A., and Steger, M. (2015). Urban
Sustainability in theory and practice, Circles of Sustainability, Routledge. [online], retrieved from; http://www.circlesofsustainability.org/wp-content/uploads/2 014/10/Ch-08-Circles-Questionnaire-2015.pdf

[24] Mokhtar, H., \& Mohammed, D. (2017). Urban sustainability evaluation of new communities in Nile delta northern coast. Mansoura University.

[25] Dehghanmongabadi, A., Hoşkara, S.O. \& Shirkhanloo, N., Introduction to achieve sustainable neighborhoods.

[26] Ibrahim, I. (2020). Sustainable Cities Indices in Modern Architecture: A Comparative Study in UAE. WIT Transactions on The Built Environment, 195.

[27] Sharjah Urban Planning Council (2019). Sharjah Neighbourhood Plan. Existing Conditions and Opportunities and Constrains Report. [unpublished].

[28] Sharjah Urban Planning Council (2017). A Study on Degraded Urban Neighborhoods. [unpublished].

[29] Ahmed, K. G. (2012). Urban social sustainability: A study of the local Emirati communities in Al Ain. Journal of Urbanism: International Research on Placemaking and Urban Sustainability, 5(1), 41-66.

[30] Derix, C., Helme, L., Galicia, F., \& Kachkaev, A. (2017). Empirically evaluating the livability of local neighborhoods and global cities. CTBUH Journal, (4), 40-47.

[31]UN-Habitat. (2013). State of the world's cities 2012/2013: Prosperity of cities. Routledge.

[32] Karban, A. S. (2014). Developing a framework for neighborhood-level urban sustainability assessment in Saudi Arabia. The University of Texas at San Antonio.

[33] LEED-ND. (2009). Leadership in Energy and Environmental Design for Neighbourhood Development. U.S.Green Building Council. 